\title{
Optimal design of cyclones in series for the separation of multi- component mixtures of Portland cement
}

\author{
Juan C. Grave', Cecilia I. Paulo ${ }^{1,2 *}$, Horacio. A. Petit ${ }^{3}$ and E. Fabián Irassar $^{2,4}$ \\ ${ }^{1}$ Departamento de Ingeniería Química, Facultad de Ingeniería, UNCPBA. Av. Del Valle 5737 - 7400 Olavarría -Argentina \\ ${ }^{2}$ Laboratorio de Micropartículas, Centro de Investigaciones en Física e Ingeniería (CIFICEN), UNCPBA-CICPBA-CONICET. Av. \\ Del Valle 5737 - 7400 Olavarría -Argentina \\ ${ }^{3}$ Department of Metallurgical and Materials Engineering, Universidade Federal do Rio de Janeiro - COPPE/UFRJ, Cx. Postal \\ 68505, CEP 21941-972 Rio de Janeiro, RJ, Brazil \\ ${ }^{4}$ Departamento de Ingeniería Civil, Facultad de Ingeniería, UNCPBA. Av. Del Valle 5737 - 7400 Olavarría -Argentina
}

\begin{abstract}
A nonlinear programming problem was developed for the separation and classification of Portland cement particles into different fractions through the optimal design of two cyclones classifier in series. The equations and restrictions considered included the global mass balances, the equations for the geometric design of the cyclones, the equations for the efficiency calculation, the operating limitations of the process and the pressure drops of the equipment. The results show that an increase on the particles cut size led to a greater dimensions cyclone, as expected. Moreover, fractional efficiencies obtained increase with the reduction of the cut size. The solids load effect is also evaluated, reductions of the solids feed by $50 \%$ of its maximum value does not result in a remarkably decrease of efficiencies values. The proposed model has provided useful information and constitutes a starting point for a better understanding of the overall separation process of multi-component Portland cement mixtures. It is a valuable tool for the correct design of this type of separators, given its versatility to optimize under different operating conditions and with different materials.
\end{abstract}

\section{Introduction}

Dust separators are widely used to obtain fine powders. Among them, the development of the technology and the optimization of cyclone separators present high academic-industrial interest and have allowed the use of this type of equipment as particle classifiers with excellent performance for particles up to $5 \mu \mathrm{m}$ in diameter [1-4]. However, the separation of multicomponent mixtures of fine powders (such as Portland cement samples) in specific cut sizes is a field that has not been studied in extent, requiring the design, simulation, optimization, and finally construction of appropriate equipment to achieve the final classification. Mixtures of particles, such as Portland cement, from natural and/or synthetic sources have high applicability, not only in the construction industry, but also in ceramics, plastics, and metallurgy. The application of powders with a specific gradation for each industry increases the added value accordingly to their size distribution.

In this work, the optimal design of two cyclone classifiers assembled in a series scheme was proposed as a first approach to achieve the separation of multicomponent Portland cement mixtures into different fractions. The cement samples were produced at a local cement industry in the central zone of the province of
Buenos Aires. The goal of the classification is to produce cement samples with cutting sizes in the range of $(5-11 \mu \mathrm{m})$. A non-linear programming problem was formulated in order to maximize the cyclone classification efficiency, taking into account the required cutting diameter, the equipment's own restrictions and the operating conditions of the separation process. This work is part of a mayor project that requires the optimization of a coupled scheme (in series or parallel layout) of 4 cyclones with different cutting sizes varying between $5 \mu \mathrm{m}$ and $45 \mu \mathrm{m}$.

\section{Materials and methods}

Stairmand High Efficiency (STHE) and High Capacity (STHC) cyclone models were considered for the optimization design. From previous works, it was demonstrated that Stairmand cyclones present a classification efficiency superior to other evaluated alternatives [1]. In this work, a new powder material was considered with the aim of developing a classification scheme, applying the STHE restrictions to the lowest cut size cyclone $(5 \mu \mathrm{m})$ and the STHC restrictions to the highest cut size $(11 \mu \mathrm{m})$. By conditioning the cyclone family, all others dimensions of the separator can be obtained as a function of its diameter. The considered

* Corresponding author: cpaulo@fio.unicen.edu.ar/ cecipaulo@gmail.com

A video is available at https://doi.org/10.48448/hqse-hb16 
cyclone models have the following geometrical proportions $[1,6]$ :

Table 1. Geometric constraints for Stairmand $\mathrm{HE}$ and $\mathrm{HC}$ cyclones.

\begin{tabular}{|c|c|c|}
\hline $\begin{array}{c}\text { Dimensionless } \\
\text { Ratio }\end{array}$ & STHE & STHC \\
\hline$a / D c$ & 0.5 & 0.75 \\
\hline$b / D c$ & 0.2 & 0.375 \\
\hline$S / D c$ & 0.5 & 0.875 \\
\hline$D s / D c$ & 0.5 & 0.75 \\
\hline$h / D c$ & 1.5 & 1.5 \\
\hline$z / D c$ & 2.5 & 2.5 \\
\hline$H / D c$ & 4 & 4 \\
\hline$B / D c$ & 0.375 & 0.375 \\
\hline
\end{tabular}

The main dimensions of a cyclone are presented and defined in Figure 1.

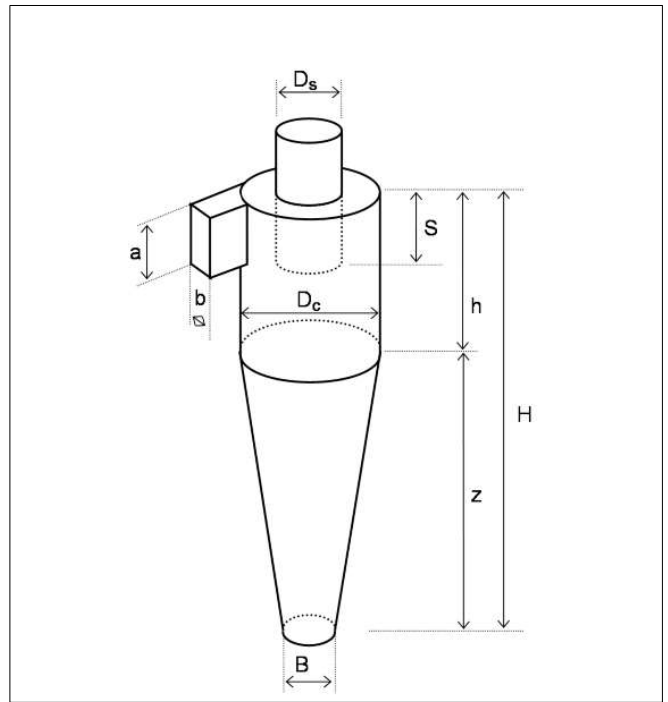

Fig. 1. Cyclone main dimensions. Tangential input. $a$ :input height; $b$ :input width; $D c$ : diameter; $B$ : bottom outlet diameter; $D s$ : top outlet diameter; $S$ : output height; $h$ : cylindrical height; $z$ : conical height; $H$ : total height.

In order to design a scheme of two cyclones in series, is of great relevance to define the cut size of each cyclone $\left(X_{50}\right)$ as a function of its operating parameters. The variable $X_{50}$ is defined as the particle size in which the forces that govern the movement of the particles are in equilibrium [2]. From particles mechanics, it is known that the particles whose diameter matches the cutting diameter have at least $50 \%$ chance of being captured in the cyclone. The cut size of a cyclone is given by the equation [2]:

$$
X_{50}=\sqrt{\frac{9 b \mu}{\pi N V e\left(\rho_{p}-\rho\right)}}
$$

where $\mu, \rho$ are the dynamic viscosity $[\mathrm{Pa} \mathrm{s}]$ and density $\left[\mathrm{kg} / \mathrm{m}^{3}\right]$ of the inlet air flow respectively, (assuming a temperature of $293 \mathrm{~K}$ ); $N$ is the number of spirals the particles make when descending into the cyclone (constant for each cyclone family, for STHE, $N=5.5$, and for STHC, $N=3.7$ ), $V e$ is the air inlet velocity $[\mathrm{m} / \mathrm{s}]$ and $\rho_{p}$ is the density of Portland cement particles $\left[\mathrm{kg} / \mathrm{m}^{3}\right]$.

To evaluate the efficiency of the cyclone, the fractional efficiency $(E k c)$ corresponding to each particle size $(k)$ is calculated from the expression presented by Dirgo and Leith $[1,2]$ :

$$
\operatorname{Ekc}(\mathrm{k})=\frac{1}{1+\left[\frac{X_{50}}{k}\right]^{6.4}}
$$

A simple model for the calculation of cyclone efficiency was considered, which fits properly for smooth and well-designed laboratory cyclones. This model has the advantage of simplifying the functionality of the $\mathrm{X}_{50}$ variable compared to others more complex models in literature.

From the consideration of the fractional efficiencies it is possible to calculate a total efficiency of the cyclone $\left(E t c_{1}\right)$ by the equation:

$$
E t c_{1}=\sum_{k=1}^{n} E k c(k) f(k)
$$

where $f(\mathrm{k})$ is the mass percentage of particles of size $\mathrm{k}$ according to the particle distribution.

The efficiency calculated by the Eq. (3) is applicable to concentrations of solids lower than 0.002 $\mathrm{kg} / \mathrm{m}^{3}\left(C_{l}\right)$, and does not consider the effect of high concentrations of solids respect to the interaction particle-particles. This phenomenon is favorable for the removal of solids at the bottom of the cyclone, then to correct the efficiency for higher particle concentrations the Smolik relation was used $[1,5]$ :

$$
E t c_{2}=100-\left(100-E t c_{1}\right)\left(\frac{C_{1}}{C_{2}}\right)^{0.182}
$$

The concentration of cement particles in the inlet air flow $\left(C_{2}\right)$ was calculated by the relationship between the air inlet flow $(Q e)$ and the stream of solids fed $\left(f_{s o l}\right)$ :

$$
C_{2}=\frac{f_{\text {sol }}}{Q e}
$$

The air inlet flow rate was limited by the fan operating limits $0.5 \mathrm{~m}^{3} / \mathrm{s}<Q e<12 \mathrm{~m}^{3} / \mathrm{s}$ and the pressure drops $(\Delta P)$ in the separator must not exceed $2488.16 \mathrm{~Pa}$ as is defined by standard for this variable [6].

The pressure drop was calculated by Sherher-Lapple model:

$$
\Delta P=\frac{1}{2} \rho V e^{2} N H
$$

where $N H$ is the number of speed heads at the cyclone inlet, and it's also a constant for each cyclone family (for STHE, $N H=6.4$ and for STHC, $N H=8$ ) [6].

The efficiency of separation in the cyclone is proportional to the air inlet velocity $(\mathrm{Ve})$, since a higher 
inlet velocity increases the centrifugal force, up to a certain recommended maximum velocity at which the collected particles undergo resuspension occurrence. This phenomenon is considered by the saltation velocity $(V S)$. A semi-empirical expression is used to determine this limit [7-9]:

$$
V S=\frac{4.913 W K b^{0.4} D c^{0.067} V e^{2 / 3}}{(1-K b)^{1 / 3}}
$$

where $K b$ is a ratio of cyclone dimensions:

$$
K b=\frac{b}{D c}
$$

and $W$ is an equivalent velocity calculated by:

$$
W=\left(\frac{4 g \mu\left(\rho_{p}-\rho\right)}{3 \rho^{2}}\right)^{1 / 3}
$$

Previous work found that the maximum cyclone efficiency was found when the gas inlet velocity $(\mathrm{Ve})$ is in a range of 1.25 and 1.35 times the saltation velocity $(V s)[1,6]$. Moreover, the available fan power in the experimental pilot plant drives air velocities in the range of $13-36.5 \mathrm{~m} / \mathrm{s}$, which are the bounds over $V e$ variable.

The corresponding algorithm was written and executed on an optimization software $\left(\mathrm{GAMS}^{\circledR}\right)$, with the restrictions defined above. Regarding the optimization algorithm used, the resolution of the nonlinear problem was carried out through the generalized reduced gradient method, implemented in CONOPT solver [10]. The objective function selected was the maximization of the separation efficiency $\left(E t c_{2}\right)$ (Fig. 3) by conditioning the $X_{50}$ variable on values of 5 $\mu \mathrm{m}$ and $11 \mu \mathrm{m}$ micrometers for each cyclone respectively. These values represent approximately $25 \%$ and $50 \%$ of the accumulated mass fraction of the particles size distribution (PSD) fed to the cyclone (Figure 2).

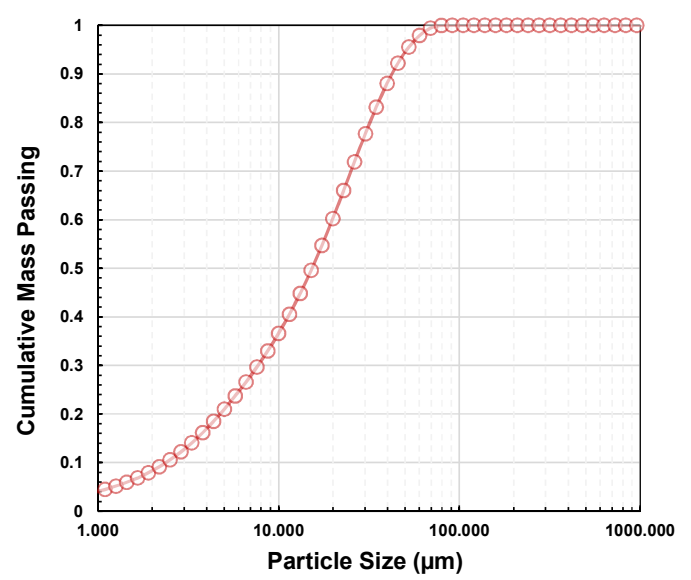

Fig. 2. PSD of Portland cement particles fed to the cyclone.

Leaving the diameter and the air velocity as independent variables, the optimal efficiencies are determined for two solid feed conditions (maximum allowable and half load). Figure 3 shows the formulation of the implemented nonlinear optimization problem.

\section{Maximize $Z_{o b j}=E t_{\mathrm{C} 2}$}

Subject to :

Eqs. [1-3]

Eqs. [5-9]

- Mass balances in process streams.

- Geometric design constraints from Table 1.

- Lower and upper bounds of each variable.

Fig. 3. Nonlinear optimization problem formulated for maximizing cyclone efficiency.

\section{Results and discussion}

Optimization results, using the solver CONOPT $3.17 \mathrm{~L}$, are reported in Tables 2 and 3.

\begin{tabular}{|c|c|c|c|}
\hline Experience & $\begin{array}{c}\boldsymbol{X}_{50} \\
{[\mu \mathrm{m}]}\end{array}$ & $\begin{array}{c}\boldsymbol{f}_{\text {sol }} \\
{[\mathrm{kg} / \mathrm{s}]}\end{array}$ & $\begin{array}{l}\boldsymbol{D} \boldsymbol{c} \\
{[\mathrm{m}]}\end{array}$ \\
\hline 1 & 5 & 0.582 & 0.597 \\
\hline 2 & 5 & 1.164 & 0.597 \\
\hline 3 & 11 & 0.582 & 0.976 \\
\hline 4 & 11 & 1.164 & 0.976 \\
\hline
\end{tabular}

Table 2. Optimal cyclone diameters for determined solid's feed $\left(f_{\text {sol }}\right)$ and cut size $\left(X_{50}\right)$.

Table 3. Inlet flow $(Q e)$, inlet velocities $(V e)$, pressure

drops and efficiencies obtained on optimization runs.

\begin{tabular}{|c|c|c|c|c|c|}
\hline Exp. & $\begin{array}{c}\boldsymbol{Q e} \\
{\left[\mathrm{m}^{3} / \mathrm{s}\right]}\end{array}$ & $\begin{array}{c}\boldsymbol{V e} \\
{[\mathrm{m} / \mathrm{s}]}\end{array}$ & $\begin{array}{c}\boldsymbol{A P} \\
{[\mathrm{Pa}]}\end{array}$ & $\begin{array}{c}\boldsymbol{E} \boldsymbol{E t c 1} \\
{[\%]}\end{array}$ & $\begin{array}{c}\boldsymbol{E t c 2} \\
{[\%]}\end{array}$ \\
\hline $\mathbf{1}$ & 0.50 & 14.05 & 736.07 & 78.68 & 93.31 \\
\hline $\mathbf{2}$ & 0.50 & 14.05 & 736.07 & 78.68 & 94.10 \\
\hline $\mathbf{3}$ & 3.547 & 13.23 & 816.77 & 60.07 & 82.10 \\
\hline $\mathbf{4}$ & 3.547 & 13.23 & 816.77 & 60.07 & 84.22 \\
\hline
\end{tabular}

The Figure 4 shows the curves of fractional efficiencies obtained as a function of particle size for both cut size cyclones studied.

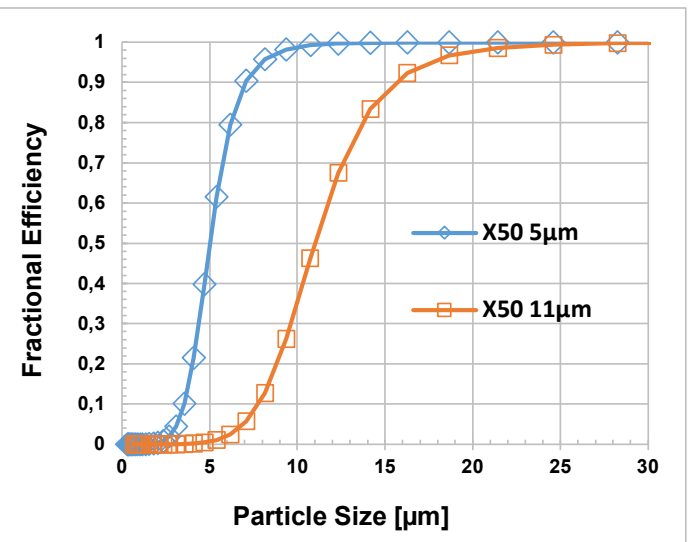

Fig. 4. Grade-efficiency curve obtained for both cyclones optimized. 
As the Barth model was applied, the curve adjusts to the expected behavior in both cyclones regardless of the solid load $\left(f_{\text {sol }}\right)$ considered; therefore, the experiences for each $X_{50}$ are superimposed on the graph, while the effect of the solid load is considered in the efficiency corrected $\left(E t c_{2}\right)$.

In order to design a cyclone that operates at the defined cut sizes, some flexibility in relation to the limits of the variables were allowed. While the cyclone determined in experiences 1 and 2 correctly fulfils all the defined restrictions, no results were obtained that verify the set of restrictions for the cut-size diameter of $11 \mu \mathrm{m}$ and higher values. Making the lower bound of the inlet velocity variable more flexible convergent results were found for the cyclones on $X_{50}=11 \mu \mathrm{m}$; and ensured to sustain the upper bound condition $(V e<1.35$ $V s$ ), as this condition guarantees that no resuspension effects will occur.

In case of experiences 1 and 2, STHE cyclones were considered based on maximizing separation efficiency. Applying this restriction and conditioning the cut size to $X_{50}=11 \mu \mathrm{m}$ results in a very large cyclone, so highcapacity cyclones (STHC) were implemented in experiences 3 and 4 .

Defining the diameter of the cyclone we can determine the remaining dimensions of the cyclone. The measures calculated for each case are presented in Table 4.

Table 4. Cyclone main dimensions obtained.

\begin{tabular}{|c|c|c|}
\hline $\begin{array}{c}\text { Cyclone } \\
\text { Dimension }\end{array}$ & $\begin{array}{c}\text { Exp. 1 and 2 } \\
\boldsymbol{X}_{\boldsymbol{5 0}}=\mathbf{5} \boldsymbol{\mu m} \\
(\mathbf{S T H E})\end{array}$ & $\begin{array}{c}\text { Exp. 3 and 4 } \\
\boldsymbol{X}_{\mathbf{5 0}}=\mathbf{1 1} \boldsymbol{\mu m} \\
(\mathbf{S T H C})\end{array}$ \\
\hline $\boldsymbol{D c} \boldsymbol{[ m ]}$ & 0.597 & 0.976 \\
\hline $\boldsymbol{a}[\boldsymbol{m}]$ & 0.298 & 0.732 \\
\hline $\boldsymbol{b}[\boldsymbol{m}]$ & 0.120 & 0.366 \\
\hline $\boldsymbol{S}[\boldsymbol{m}]$ & 0.298 & 0.854 \\
\hline $\boldsymbol{D} \boldsymbol{s}[\boldsymbol{m}]$ & 0.298 & 0.732 \\
\hline $\boldsymbol{h}[\boldsymbol{m}]$ & 0.895 & 1.464 \\
\hline $\boldsymbol{z}[\boldsymbol{m}]$ & 1.493 & 2.440 \\
\hline $\boldsymbol{H}[\boldsymbol{m}]$ & 2.388 & 3.905 \\
\hline $\boldsymbol{B}[\boldsymbol{m}]$ & 0.224 & 0.366 \\
\hline
\end{tabular}

From the results obtained, it is observed that the trend in the values obtained is consistent with the definition of the model made and the equations presented. As we expected, the increase on the cut size conditioned $\left(X_{50}\right)$ led to a greater dimensions cyclone and the efficiencies obtained were higher when the cut sizes were lower.

The solids load effect showed an increase on cyclone separating-efficiency, exposed on the difference between $E t c_{1}$ and $E t c_{2}$. On the other hand, reducing the solids feed flow rate by $50 \%$ of the maximum value does not result in a remarkably lower efficiency (as we can see comparing the experiences 1 and 2, or 3 and 4). This result is interesting, according to the volume of solids that needs to be processed, the operation can be adjusted to lower solids feed rates without a notable reduction in efficiency. Reduction of solids feed allows reduction in process operating costs.

Next step of this work will be to continue improving the classification scheme considering other particle dynamics and efficiency models, in order to specify not only these two cyclones but also two others with higher cut sizes $\left(X_{50}=22 \mu \mathrm{m}\right.$ and $\left.X_{50}=45 \mu \mathrm{m}\right)$ according to the requirements for separation of multi-component mixtures in the cement and ceramic industry. Furthermore, the construction of the cyclones and the corresponding experimental data acquisition are planned to adjust the mathematical models and provide separation services to interested industries.

\section{Conclusions}

A pair of cyclones was designed running an optimization code. As a result of that implementation satisfactory results were obtained for two characteristic cut sizes $\left(X_{50}\right): 5 \mu \mathrm{m}$ and $11 \mu \mathrm{m}$. The experiences developed were successful to obtain two cyclones of optimal efficiency within multiple ranges of restrictions for the characteristic variables of cyclone-dynamics.

This work constitutes a first approach to a complex problem: the issues related to the coupling of the cyclones and the modifications in the distribution of particles fed to each cyclone. The result of having been treated by a previous stage of particles separation has not been considered, since they have been considered individually.

As future work these results will be taken into consideration for condition the programmed code and the equations system presented. The objective will be to advance in the design of an integrated cyclone scheme (series or parallel arrangements) to classify the distribution into four diameter intervals. Partial results obtained in this work are useful to understand the behavior of the system under the defined restrictions and flow models, and represent a starting point in the study of the separation of multi-component powder mixtures.

\section{References}

[1] C.I. Paulo, E. Borsa, M.R. Barbosa, Int. J. Sustain. Eng. 11, 240 (2018)

[2] S. Venkatesh, R.S. Kumar, S.P. Sivapirakasam, M. Sakthivel, D. Venkatesh, S. Yasar Arafath, Powder Technol. 371, 115 (2020)

[3] F. Mariani, F. Risi, C.N. Grimaldi, Sep. Purif. Technol. 179, 393 (2017)

[4] L. Qiang, W. Jianjun, X. Weiwei, Z. Meng, Adv Powder Technol. 31, 3706 (2020)

[5] A.C, Hoffmann, L.E. Stein, Gas Cyclones and Swirl Tubes. Principles, Design and Operation (Springer, $2^{\text {nd }}$ Ed. 2008)

[6] C.A. Echeverri Londoño, Rev. Ing. Univ. Medellin 5, 123 (2006)

[7] B. Kalen, F.A Zenz, AIChE J. 70, 388 (1974)

[8] M. Berezowski, K. Warmuziski, Chem. Eng. Process.: Process Intensification 32, 345 (1993)

[9] X. Chen, J.J. Dong, J. Chen, Chem. Eng. Process.: Process Intensification 34, 379 (1995)

[10] A. Brooke, D. Kendrick, A. Meeraus, GAMS: A Users Guide (Scientific Press, Palo Alto, Ca. 2008) 